\title{
Disc battery ingestion: A rare cause of perforation of the brachiocephalic artery
}

\author{
Donovan P. Loots, Lorraine du Toit-Prinsloo*, Gert Saayman
}

Affiliation and addresses of the authors:

DP Loots:

Medical Officer; University of Pretoria; Department of Forensic Medicine, Private Bag X323, Arcadia, 0007 SOUTH AFRICA

BSc, MBChB, DipPEC(SA), DipForMed(SA)Path

L du Toit-Prinsloo: $\quad$ Specialist / Lecturer; University of Pretoria; Department of Forensic Medicine, Private Bag X323, Arcadia, 0007 SOUTH AFRICA

MBChB, DipForMed(SA)Path, FCForPath(SA), MMed(Path)(Forens)

G Saayman:

Chief specialist / Head of Department; University of Pretoria; Department of Forensic Medicine, Private Bag X323, Arcadia, 0007 SOUTH AFRICA MBChB, MMed(Med)(Forens), FCForPath(SA)

*E-mail address, telephone and fax numbers of the corresponding author:

L du Toit-Prinsloo

Email:

lorraine.dutoit@up.ac.za

Telephone numbers: $\quad+27(0) 123235298$ (work)

Fax number: $+27(0) 834064056$ (mobile) +27(0)123230921

\section{Case report}

A previously healthy 2 year old female toddler was brought to the emergency department with a history of severe hematemesis. Posterior-Anterior (PA) and lateral chest radiographs demonstrated a round radio-opaque object (approximately the size of a U.S. quarter coin) in the esophagus (figure 1). A pediatric surgeon was consulted for endoscopic removal of the foreign body, but the child's condition deteriorated rapidly and despite full resuscitative efforts, the child demised before the foreign object could be removed.

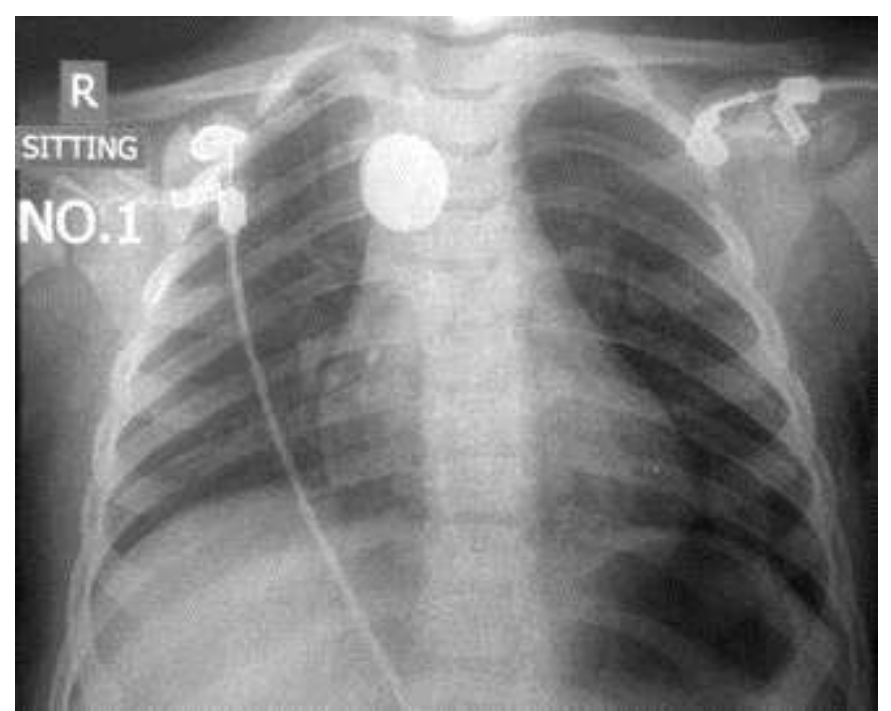

Fig. 1. PA X-ray of the chest depicting the presence of the foreign body (disk battery) in the esophagus

Lodox ${ }^{\circledast}$ Statscan performed prior to commencement of the autopsy confirmed the presence of the foreign object in the esophagus. Externally, signs of resuscitation efforts were found, as well as pallor of the mucosal surfaces. Dissection revealed a right sided hemothorax of approximately $25 \mathrm{ml}$, with no rib fractures. There was a perforating defect of the posterior wall of the esophagus, measuring $20 \mathrm{~mm} \mathrm{x}$ 
5mm, with a disc battery (model CR2032) wedged in situ within the defect, with surrounding superficial mucosal sloughing and signs of reactive induration and inflammation (figure 2). The perforating defect extended to involve the subjacent brachiocephalic artery (innominate artery), immediately distal to the point of origin from the aortic arch (figure 3 ). The disc battery measured $20 \mathrm{~mm}$ in diameter and $3.2 \mathrm{~mm}$ in thickness (figure 4). Further dissection revealed the presence of blood in the stomach, duodenum and jejenum.

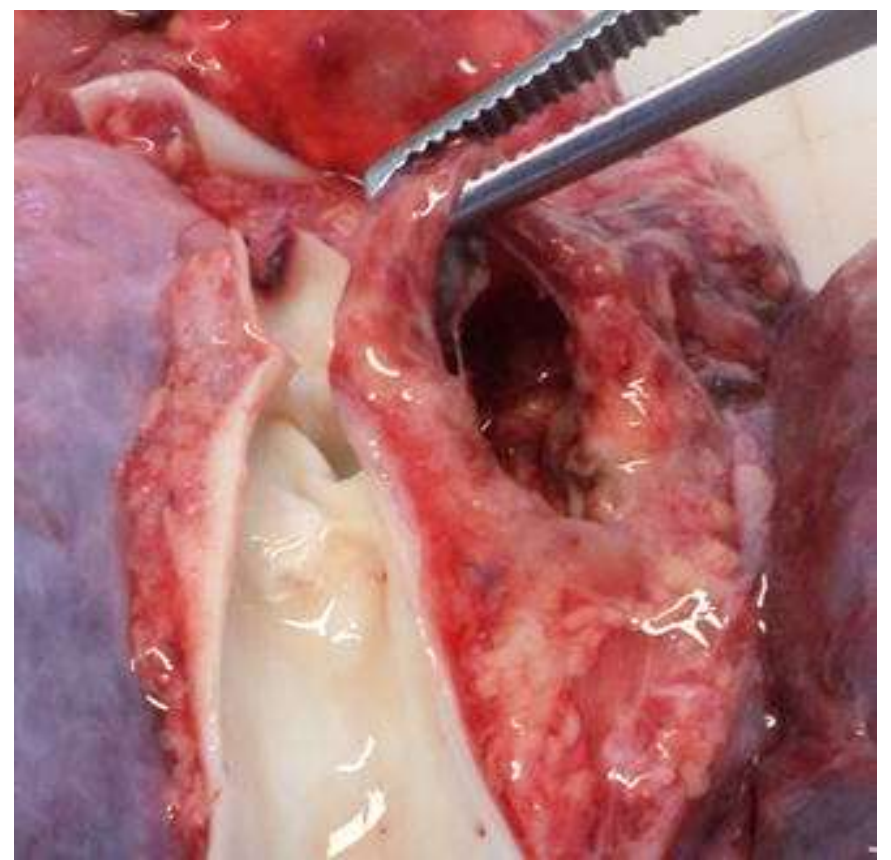

Fig. 2. The posterior aspect of the esophagus and aorta showing the perforating defect through the posterior wall of the esophagus

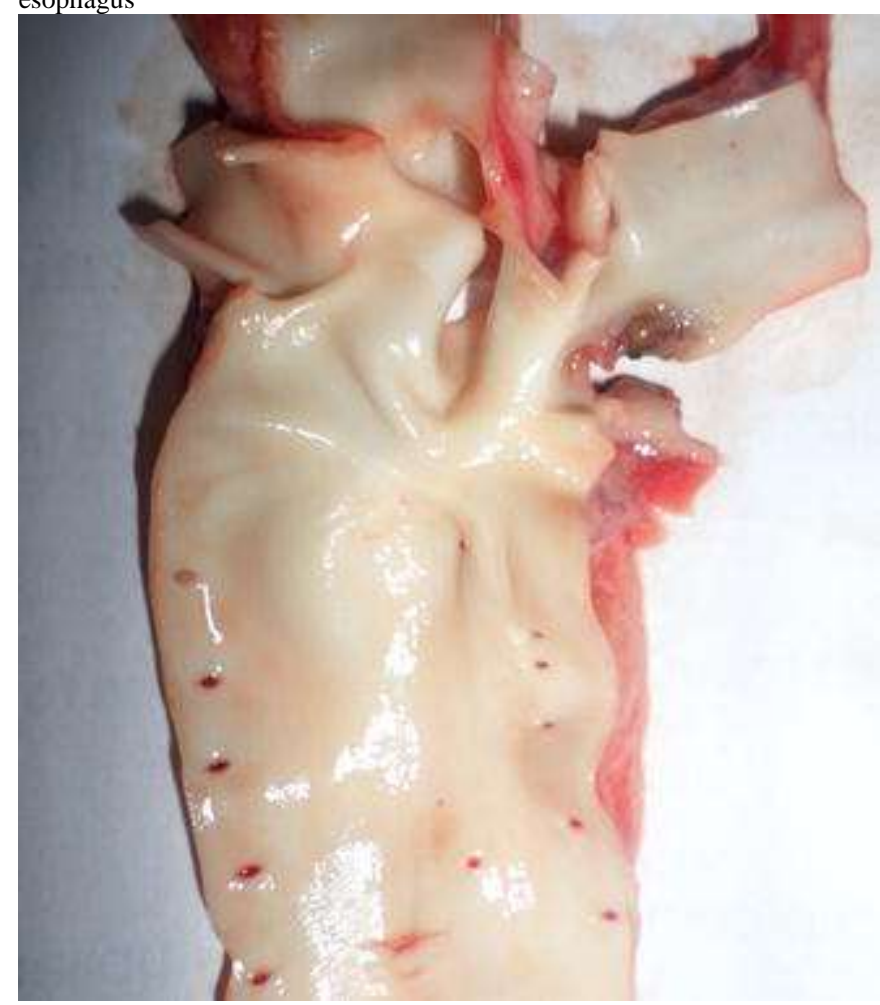

Fig. 3. A posterior view of the aorta showing its branches and depicting the perforating defect through the brachiocephalic artery on the right 


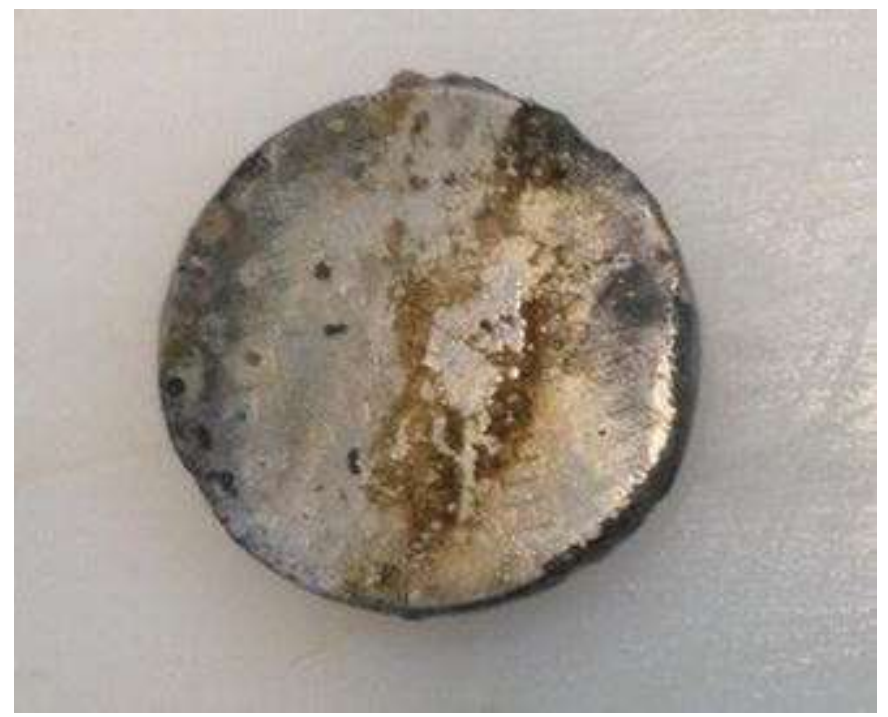

Fig. 4. The foreign body (disk battery) retrieved from the esophagus

Histological examination of the esophagus showed transmural infiltrate of predominantly chronic inflammatory cells with minimal neutrophils and eosinophils (figure 5). Sections from the brachiocephalic artery showed a florid acute inflammatory reaction with numerous neutrophils and eosinophils and with minimal lymphocytes in the adventitial layers.

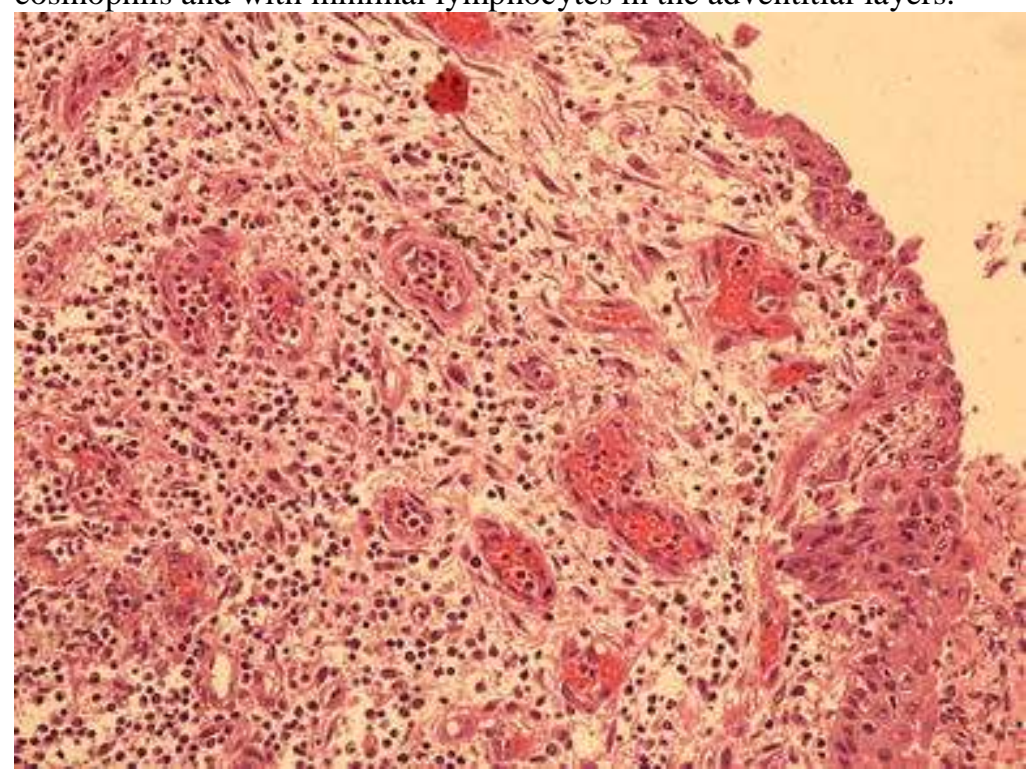

Fig. 5. Histological section of the esophagus showing predominantly chronic inflammatory cells in the submucosa

Based on the overall history and findings, we concluded that the battery had been ingested approximately two weeks prior to the child's demise, lodging within the esophageal lumen where it subsequently eroded the mucosa and posterior wall and later into the brachiocephalic artery. The corrosive effect led to intermittent hemorrhage into the gastrointestinal tract and the subsequent severe pre-terminal hematemesis.

We could not trace any previous published reports of esophageal perforation with associated brachiocephalic artery injury and severe hemorrhage as a result of ingestion of a disc/button battery.

\section{Discussion}

Ingestion of a foreign body is a common and increasing occurrence in pediatric patients presenting to the emergency departments worldwide.[1] Approximately $40 \%$ of foreign body ingestions are either unwitnessed or unrecognized and may be either asymptomatic or present later with non-specific 
symptoms.[1,2] Fatalities can occur if an ingested battery lodges in the esophagus and injuries extend beyond the esophagus to the trachea, aorta, other vessels and mediastinal organs.[2,3] The recent increase in the production of larger, more powerful button batteries has coincided with more frequent reporting of fatal hemorrhage secondary to battery impaction and esophageal perforation.[3] Fatal cases should undergo medico-legal investigation, yet there appears to be paucity of published literature in forensic pathology journals.

The first case of a perforating esophageal injury caused by an ingested disc battery was reported in 1977, a camera battery having eroded the esophagus and inferior thyroid vessels, causing extensive hemorrhage and death.[3, 4] The Center for Disease Control and Prevention (CDC) in the United States of America (USA) has reported that an estimated 40400 children under the age of 13 years were treated in hospital emergency departments for battery-related injuries, for the period 1997-2010 including 14 fatalities. Furthermore, there was 2.5-fold increase observed in the annual number of battery related cases, from 1900 cases in 1998 to 4800 in 2010. [5] Several studies have indicated that most children who ingested batteries were $\leq 6$ years of age. $[2,6,7,8]$ The National Capital Poison Center reported a total of 39 fatal cases of button battery ingestion in the USA from 1977-2014.[9] Reasons proposed for this dramatic increase are that there is an increase in production of larger, more powerful button batteries and more battery-powered electronic devices are being used by children.[2, $3,8]$

In South Africa (SA), there is a paucity of published data relating to the ingestion of these foreign bodies and in particular, a scarcity of data on fatal outcomes associated with disc battery ingestion. It would appear that the only institution collecting or reporting such data is the Red Cross War Memorial Children's Hospital (RCWMCH) in Cape Town. These data (although from a small sample set and thus most likely not fully representative of the rest of the country) appear to correlate with the statistics provided by the National Poison Center Data System in the USA. Data gathered from 1983 to 1985 at RCWMCH reported 13 cases of button battery ingestion and none were fatal.[10] Balme et al (2012), reported only 9 cases of battery ingestion from 2003-2008 at the same hospital, with no fatalities documented.[11]

Child Safe South Africa is a non-profit organization based in Cape Town and currently the only agency of this nature maintaining a pediatric injury database in SA. Statistics of battery ingestion in children from 2009-2013 showed that a total of 34 reported cases were treated at the Red Cross War Memorial Children's Hospital during this period.[12] This is significantly higher than the number of cases reported by Balme et al in 2012.[11, 12] However, the specific type of battery which had been ingested and the number of fatal outcome cases were not reported upon.

It has been reported that disc batteries cause esophageal tissue injury through multiple interacting mechanisms. These mechanisms are activated, not when a battery is free-floating in the gastrointestinal tract or in transit, but rather when it becomes lodged within the lumen or at an orifice. The mechanisms of injury include:

- Generation of an electrolytic/electrochemical current which hydrolyzes tissue fluids and produces hydroxide at the anode (negative pole) of the battery;

- Leakage of alkaline electrolyte battery contents (hydroxide);

- $\quad$ Physical pressure on adjacent tissues (does not cause significant injury on its own).[3,4,8,13]

The most common location where a foreign body may be found in the gastrointestinal tract is in the stomach $(60 \%)$, followed by the esophagus (20\%), intestines $(10 \%)$, and lastly the oropharynx (5$10 \%)$. A foreign body may become lodged in the esophagus at the site of normal physiological narrowing or at a pre-existing area of abnormality such as at a tracheoesophageal fistula or vascular ring. [1]

Blunt foreign bodies may become lodged in the esophagus because of weak peristalsis and anatomical / physiological narrowing. [13] Approximately 70\% of foreign bodies ingested become lodged at the upper esophageal sphincter or thoracic inlet (at the level of the clavicles on chest X-ray).[1] Approximately $15 \%$ become lodged in the mid esophageal region (where the aortic arch and carina overlap the esophagus on chest X-ray) and the remaining $15 \%$ become lodged in the lower esophageal sphincter (LES) or at the gastroesophageal junction.[1] 
Radiological imaging is the primary diagnostic tool for identifying ingested foreign bodies.[1-4] Plain anteroposterior (AP) and lateral radiographs of the neck, chest and abdomen should be obtained to verify the location and to better identify the foreign body.[1-3] Coins will most often display a smooth border, whereas button/disc batteries may show a typical halo sign in an AP radiograph (inner ring just inside the outer ring). If the object is in the esophagus, a lateral X-ray may assist in the recognition and localization of the foreign body. The button battery may have a distinctive two-step border on a lateral film. [1] Post mortem radiology as an ancillary investigation is now available at many mortuaries, with the use of conventional and digital X-ray equipment, CT scanning and even MRI scans - all of which may be very valuable in assisting the pathologist in identifying and localizing a foreign object in the body. The possibility of aberrant or altered anatomy should always be entertained. Soerdjbalie-Maikoe et al reported a case esophageal perforation into an aberrant right subclavian artery (arteria lusoria).[14]

Since the case reported in 1977 there have only been 39 reported cases of fatal outcome ingestion of button battery in the USA.[3,9] None of these were reported to have been specifically associated with perforation of the brachiocephalic artery.[9] This specific injury thus appears to be a rare outcome of disc battery ingestion and to our knowledge this may be the first reported case of its kind.

In our case, features of chronic inflammation in relation to the foreign object correlate with the clinical history of probable ingestion some two weeks earlier. Signs and symptoms in keeping with an upper respiratory tract infection were apparently initially misinterpreted by clinicians. Primary health care workers will be well advised to include the ingestion of these foreign bodies in their differential diagnosis in such cases and to contemplate the judicious use of radio-imaging as an aid to diagnosis. Low dose digital $\mathrm{x}$-ray scanning may be a very valuable tool in this regard.

\section{References}

1. Stebel M, Hoyt KS, Magit A. Esophageal foreign body in a 13 month-old. AENJ 2010; 32(1): 7-19.

2. Brumbaugh DE, Colson SB, Sandoval JA, Karrer FM, Bealer JF, Litovitz T, et al. Management of button battery-induced hemorrhage in children. J Pediatr Gastroenterol Nutr 2011; 52(5):585-589.

3. Kimball SJ, Park AH, Rollins MD, Grimmer JF, Muntz H. A Review of Esophageal Disc Battery Ingestions and a Protocol for Management. Arch Otolaryngol Head Neck Surg. 2010; 136(9):866-871.

4. Litovitz T, Whitaker N, Clark L, White NC, Marsolek M: Emerging battery ingestion hazard: Clinical implications. Pediatrics 2010;125(6): 1168-1177.

5. The Centers for Disease Control and Prevention (CDC) [internet], Morbidity and Mortality Weekly Report (MMWR) 2012:61(34);661-666, Injuries from Batteries Among Children Aged <13 Years - United States, 1995-2010. [cited 2015 May 06]. Available from: http://www.cdc.gov/mmwr/preview/mmwrhtml/mm6134a1.htm

6. Sharpe SJ, Rochette LM, Smith GA. Pediatric Battery-Related Emergency Department Visits in the United States, 1990-2009. Pediatrics 2012;129(6)1111-1117.

7. Slamon NB, Hertzog JH, Penfil SH, Raphaely RC, Pizarro C, Derby CD. An unusual case of button battery-induced traumatic tracheoesophageal fistula. Pediatr Emerg Care 2008;24:313-6.

8. Rohatgi S, Larson-Nath C, Chelimsky G, Werlin SL. Disc Battery Ingestion: Aggressive or conservative Management? J Pediatr Gastroenterol Nutr. 2014 Oct 8. [Epub ahead of print]

9. National Capital Poison Center [internet], Fatal Button Battery Ingestions: 39 Reported Cases. [cited 2015 Mar 26]. Available from: http://www.poison.org/battery/fatalcases.asp 
10. Millar AJW, Rode H, Cywes S, van der Walt F. Button-battery ingestion - a hazard of modern living. S Afr Med J. 1985: 68; 868-871.

11. Balme K, Roberts JC, Glasstone M, Curling L, Mann MD. The changing trends of childhood poisoning at a tertiary children's hospital in South Africa. S Afr Med J. 2012;102;142-146.

12. Childsafe / Child Accident Prevention Foundation of Southern Africa [internet]. [cited 2015 May 20] Available from: http://www.childsafe.org.za

13. National Capital Poison Center [internet], Mechanism of battery-induced injury. [cited 2015 Mar 26]. Available from: http://www.poison.org/battery/mechanism.asp

14. Soerdjbalie-Maikoe V, van Rijn RR. A case of fatal coin battery ingestion in a 2-year-old child. Forensic Sci Int. 2010;198(1-3):e19-22. 